\title{
Perceptions of Challenges Affecting Research Ethics Committees' Members at Medical and Health Science Colleges in Omani and Jordanian Universities
}

\author{
Omar Al Omari ${ }^{1,2} \cdot$ Atika Khalaf $^{1,3}$ (D) Wael Al Delaimy ${ }^{4} \cdot$ Mohammad Al Qadire $^{1,5}$. \\ Moawiah M. Khatatbeh ${ }^{6} \cdot$ Imad Thultheen $^{7}$
}

Accepted: 12 March 2021 / Published online: 9 April 2021

(C) The Author(s) 2021

\begin{abstract}
In recent years there has been an increase in research conducted in the Middle East, with a corresponding increase in the challenges faced by members of the Research Ethics Committees (RECs). This study compares the structures of Omani and Jordanian RECs and investigates the perceptions of the challenges affecting the work of the REC members in Oman and Jordan. A convenience sample of 34 Omani and 66 Jordanian participants from 21 universities was recruited in this cross-sectional study. Almost $70 \%$ disagreed that the members of RECs are unqualified, providing comments without justification; half believed that members have limited experience in research, and almost three-quarters that they have different opinions regarding some ethical issues. No significant differences were found between Omani and Jordanian REC members regarding their perception of the challenges, except for the perception that reviewing proposals is a time-consuming task $(p=0.048)$ and that multi-REC centres are less available $(p=0.026)$. The regression model showed that there were significantly more male members of Jordanian RECs, and that Jordanian members were less likely to receive formal training. In conclusion, the current structure of RECs and the challenges faced by members need to be re-evaluated by decision makers to improve the overall quality of research activities, and to ensure that current REC members' practices adhere to international standards.
\end{abstract}

Keywords Perceived qualifications · Members' bias · Misconduct - Management issues · Ethical challenges

\section{Introduction}

Recent years have witnessed an increasing amount of research conducted in Arab countries, putting pressure on governments to protect human rights (Silverman et al., 2015). Some countries responded early to this call; for example, Lebanon's American University of Beirut (AUB) in 1994 established the first institutional review board in an Arab

Atika Khalaf

atika.khalaf@hkr.se

Extended author information available on the last page of the article 
country (American University of Beirut (AUB), 2020). Some countries, including Jordan and Sudan, established a Clinical Research Law in 2001, which requires researchers to adhere to ethical principles (National Ministry of Health [Sudan], 2015; Ramahi \& Silverman, 2009), while others, including Oman, declared that clinical trials could not be executed without permission from the Medicines Regulatory Authority and the Central Research Ethics Committee of the Ministry of Health, which in turn requested researchers to register trials with the Omani National Clinical Trials and NLM Clinical Trials (Centre of Studies and Research Directorate General of Planning and Studies, 2016; Ministry of Health [Oman], 2011). However, other Arab countries, including Egypt and Yemen, did not introduce such laws (Silverman et al., 2013).

Research institutions and funding bodies responded to the increased amount of research and established Research Ethics Committees (RECs), which are mainly responsible for protecting people or animals involved in any research (World Medical Association (WMA), 2008). This means taking responsibility for peer review of proposals and making recommendations to maintain ethical standards; assessing proposals and ensuring that the suggested recommendations are addressed and ethical standards maintained; approving or rejecting research proposals based on their ethical status; monitoring projects and ensuring the process is implemented according to the proposal and ethical standards; solving any ethical problem concerning the research that may arise between researchers; and terminating the research at any implementation phase, when the committee observes potential extreme harm to participants under study (Beirut Arab University, 2017; Grady, 2015; Kass et al., 2007).

A REC is composed of members from different specialties, who meet regularly and have a good level of awareness of the potential risks to all parties involved in the research process (Grady, 2015). In Jordan the councils have at least five members, one of whom has a legal background; one is a member of the community; and physician, and members from both sexes are represented (Shafout \& Mahrouq, 2014). The community member is responsible for guarding the interests and well-being of participants and the legal representative for providing legal advice to members (World Health Organization, 2009). Only 11 RECs are officially registered in Jordan with membership meeting these criteria; other RECs are run by academic institutions but do not necessarily have legal and community representatives (Shafout \& Mahrouq, 2014). The REC members are recruited by direct nomination by the dean or head of the department or the chancellor who formulates the final list of the committee. In Oman, university RECs are composed of a panel of physicians and faculty representatives from the Nursing College. The board members are usually nominated by the Dean and approved by the University's Vice Chancellor. The REC members at the Ministry of Health level are nominated by the Minister of Health and the board includes members from different health disciplines. The legal representative under this constitution is not a regular member but is consulted when needed. In both Jordan and Oman, the RECs in Nursing Colleges consist only of a nurse who holds a PhD.

Several studies have been conducted to evaluate the RECs from researchers' perspectives, concluding, for example, that members spend too long reviewing proposals, delaying the research (El-Dessouky et al., 2011; Grady, 2015; Makhoul et al., 2014); and that members should possess certificates in research ethics (Rababa'h, 2020). They also believed that their research proposals during the review process may be subjected to potential conflicts of interest and bias (Ayoub et al., 2019), and in general, that researchers do not well understand the role of RECs (Tarboush et al., 2020). From the opposite perspective, members of RECs reported several challenges, including: limited experience of the members of ethics committees; limited ability to prolong membership of the members; limited 
ability to sustain qualified members (Matar \& Silverman, 2013; Sleem et al., 2010); different opinions regarding the same proposal; extended time spent in reviewing the proposals (Nyika et al., 2009); too much bureaucracy in taking decisions; and possible hidden agendas between members. That is, REC members are biased when they assess the risks and benefits of a study being done by a close colleague or collaborator (Clapp et al., 2017; Glasa et al., 2015). Overall, the ability of RECs to apply high-quality standards has been questioned in previous research (Bhutta, 2002; Hyder et al., 2004).

Globally there is a plethora of research investigating the challenges and functions of RECs from researchers' perspectives, but little exploring this issue from REC members' perspectives and even less investigating this issue in Middle East countries like Oman and Jordan (Guillemin et al., 2012). The aim of the current study was therefore to compare the structures of Omani and Jordanian RECs and to investigate members' perceptions of the challenges affecting their work.

\section{Methods}

\section{Design}

A comparative cross-sectional study was conducted between December 2018 and August 2019.

\section{Inclusion Criteria}

An academic member who is serving or has previously served on a REC of the following colleges: (1) Medicine; (2) Nursing; (3) Pharmacy, and/or (4) Health Sciences, and is currently working in an academic institution in Oman and/or Jordan.

\section{Sampling}

Convenience sampling was used to recruit participants from three universities in Oman and 15 in Jordan. The choice of the universities was based on whether the university had an ethical committee or not. Oman and Jordan were selected as study settings because the two countries share common characteristics concerning research ethics policies and regulations; that is, all research needs to be approved by the REC before it is conducted. The REC members have relatively limited training and experience, with little ethical certification. Both countries have developing economies. Moreover, the authors of the current study are working in these two countries and have access to the researchers.

\section{Data Collection Technique}

The principal researcher prepared a list of universities with Medical and/or Health Sciences Faculties. The list was then used to search for faculty members whose contact information was published on their respective university's homepage. A survey was uploaded to Google Forms and a link was sent via email to all faculty members of Jordanian and Omani Higher Education Institutions. All faculty members were targeted because the researchers were unable to retrieve data about those who were currently or had previously served on 
RECs. Five hundred emails were sent, but only 100 were completed. The data collection took longer than expected and as a result, it was decided that the survey should end when it reached 100 participants.

\section{Survey}

A survey questionnaire was developed by the researchers based on the literature. It was composed of two parts, the first on demographics including location, age, the faculty that the respondent currently works at; position of the faculty member, and the number of indexed published papers. The second section comprised 12 items stating the major challenges that affect the work of the REC, with responses measured on a 4-point Likert scale: strongly disagree, disagree, agree or strongly agree. The validity and reliability of the survey questionnaire were established through a pilot stage with 30 respondents, prior to sending the rest of surveys to the participants. The Test-retest reliability (Cronbach's alpha) was established (0.858). Responses from the pilot testing were not included in the final analysis.

\section{Ethics}

This proposal was approved by the Ethics Committee of the College of Nursing at Sultan Qaboos University (Protocol no. 18/2018). Participants contacted by email were assured that the information they provided would be treated anonymously and that they had the right to withdraw at any time and not to answer every question in the survey. The email included a brief introductory statement about the purpose of research. A clear statement was given to participants that accessing the questionnaire was considered as giving consent to take part in the study. However, and to maintain the anonymity of the participants, the Google Forms was programmed not to link the participants' responses with their emails ID; hence, their consent was not documented. All data were stored in a computer protected by password, to which only the principal investigator had access.

\section{Analysis}

Data were downloaded from the Google Forms website as a CSV file and exported to an Excel spreadsheet, then exported to SPSS. Descriptive statistics with means, standard deviations, and frequencies were reported to describe the sample characteristics.

All analyses were initiated with operationalizing all the variables to be included in the analyses. New variables were created to better describe the challenges met by the participants; three items were grouped to build "Qualification and experience", three items built "Members' bias", five items built "Management issues", and one item was selected to describe "Misconduct issues". The values of these items were summed before being tested for distribution and descriptive measures to decide cut-off points for the new variables. In addition, variables with low rates in some response categories were recategorized or merged as applicable.

In the last step, a logistic regression analysis was conducted using Enter method at $p \leq 0.05$ to identify factors associated with being a REC member in Oman or in Jordan. The independent variables included in the final equation were: Age, Gender, Organization form, Currently member of REC/IRB, Experience in years, Number of members in 
the REC, Selection of members, Number of primary reviewers, Decision making, Formal training, Required education, Qualifications of members, Bias in members, Management issues, Misconduct issues, and Profession.

\section{Results}

One hundred participants completed the survey. Two-thirds of the participants were from Jordan. 58\% were male and 66\% were from government institutions. The mean age of the participants was 45 years, and almost half were from a College of Nursing (47\%); the other professions were distributed as follows: College of Medicine 21\%, College of Pharmacy $14 \%$, College of Health Sciences 12\%, and College of Dentistry 6\%. The participants' demographics are presented in Table 1.

A group comparison between Omani and Jordanian REC members revealed significant differences in gender $(p=0.004)$, being currently a member in REC $(p=0.008)$, and if the participants had received formal ethical training $(p=0.011)$ (Table 2).

Table 3 shows the background of RECs in Jordan and Oman on a group level. On average, a REC has 6.62 members (min-max $=2-20$ ), and they meet on average nine times a year $(\min -\max =1-24)$. Each proposal is reviewed by three reviewers on average $(\mathrm{m}=2.86$; $\min -\max =1-10)$. The majority of members $(90 \%)$ were appointed to the REC and $74 \%$ of them were not required to have previous ethical training. Decisions about ethical issues were made during committee meetings by $47 \%$ consensus agreement and $30 \%$

Table 1 Demographics of participants presented in $n=$ valid percent since the total $n=100$

\begin{tabular}{ll}
\hline Item & $\mathrm{n}=100$ \\
\hline
\end{tabular}

Age $(M=45 ; S D=8 ; \min -\max =29-66)$

Location

$\begin{array}{ll}\text { Oman } & 34 \\ \text { Jordan } & 66\end{array}$

Gender

Female 42

Male 58

Type of institution

Governmental institutions $\quad 66$

Private institutions 34

College

College of Health Sciences $\quad 12$

College of Dentistry 6

College of Medicine 21

College of Nursing $\quad 47$

College of Pharmacy 14

Academic Rank

Full Professor $\quad 15$

Associate Professor 30

Assistant Professor 43

Lecturer 12 
Table 2 A group comparison between Omani and Jordanian research ethics committee members' characteristics, presented in $\mathrm{n}(\%)$

\begin{tabular}{|c|c|c|c|}
\hline Variable & Oman, $\mathrm{n}=34$ & Jordan, $\mathrm{n}=66$ & $p$-value \\
\hline Gender & & & 0.004 \\
\hline Male & $13(38.2)$ & $45(68.2)$ & \\
\hline Female & $21(61.8)$ & $21(31.8)$ & \\
\hline College & & & 0.161 \\
\hline Medicine & $6(17.6)$ & $15(22.7)$ & \\
\hline Pharmacy & $2(5.9)$ & $12(18.2)$ & \\
\hline Health Sciences & $7(20.6)$ & $11(16.7)$ & \\
\hline Nursing & $19(55.9)$ & $28(42.4)$ & \\
\hline Academic rank & & & 0.271 \\
\hline Full Professor & $0(0.0)$ & $15(22.7)$ & \\
\hline Associate Professor & $9(26.5)$ & $21(31.8)$ & \\
\hline Assistant Professor & $19(55.9)$ & $24(36.4)$ & \\
\hline Lecturer & $6(17.6)$ & $6(9.1)$ & \\
\hline Type of institution & & & 0.373 \\
\hline Governmental & $20(58.8)$ & $46(69.7)$ & \\
\hline Private & $14(41.2)$ & $20(30.3)$ & \\
\hline Currently member in REC/IRB & & & 0.008 \\
\hline Yes & $10(29.4)$ & $38(57.6)$ & \\
\hline No & $24(70.6)$ & $28(42.4)$ & \\
\hline Selection of members & & & 0.731 \\
\hline Volunteer & $4(11.8)$ & $6(9.1)$ & \\
\hline Appointed & $30(88.2)$ & $60(90.9)$ & \\
\hline Required education & & & 0.167 \\
\hline Yes & $13(38.2)$ & $16(24.2)$ & \\
\hline No & $21(61.8)$ & $50(75.8)$ & \\
\hline Formal training & & & 0.011 \\
\hline Yes & $23(67.6)$ & $26(39.4)$ & \\
\hline No & $11(32.4)$ & $40(60.6)$ & \\
\hline Decision making & & & 0.420 \\
\hline Majority vote & $12(35.3)$ & $18(27.3)$ & \\
\hline Expert recommendation & $2(5.9)$ & $10(15.2)$ & \\
\hline Consensus agreement & $15(44.1)$ & $6(9.1)$ & \\
\hline Other & $5(14.7)$ & $32(48.5)$ & \\
\hline
\end{tabular}

Pearson Chi-Square (Fisher's exact test when applicable). Mann-Whitney U-test

$(n=29)$ by majority vote. Formal minutes were recorded at $77 \%$ of the meetings. Half of the participants $(51 \%)$ had not received formal ethical training.

The original analysis plan was to use the 4-point Likert scale, but given the distribution of answers in certain categories (e.g. "strongly agree", "strongly disagree" had low response rates), we merged the categories to enable the analysis. To make the results more meaningful, "strongly agree" and "agree" were combined, as were "strongly disagree" and "disagree", in the reporting of the results; however, detailed frequencies are provided in 
Table 3 Background facts on RECs work on a group level (i.e. in both Jordan and Oman) presented in means $(\mathrm{m})$, Standard Deviations $(S D)$, and $\mathrm{n}$

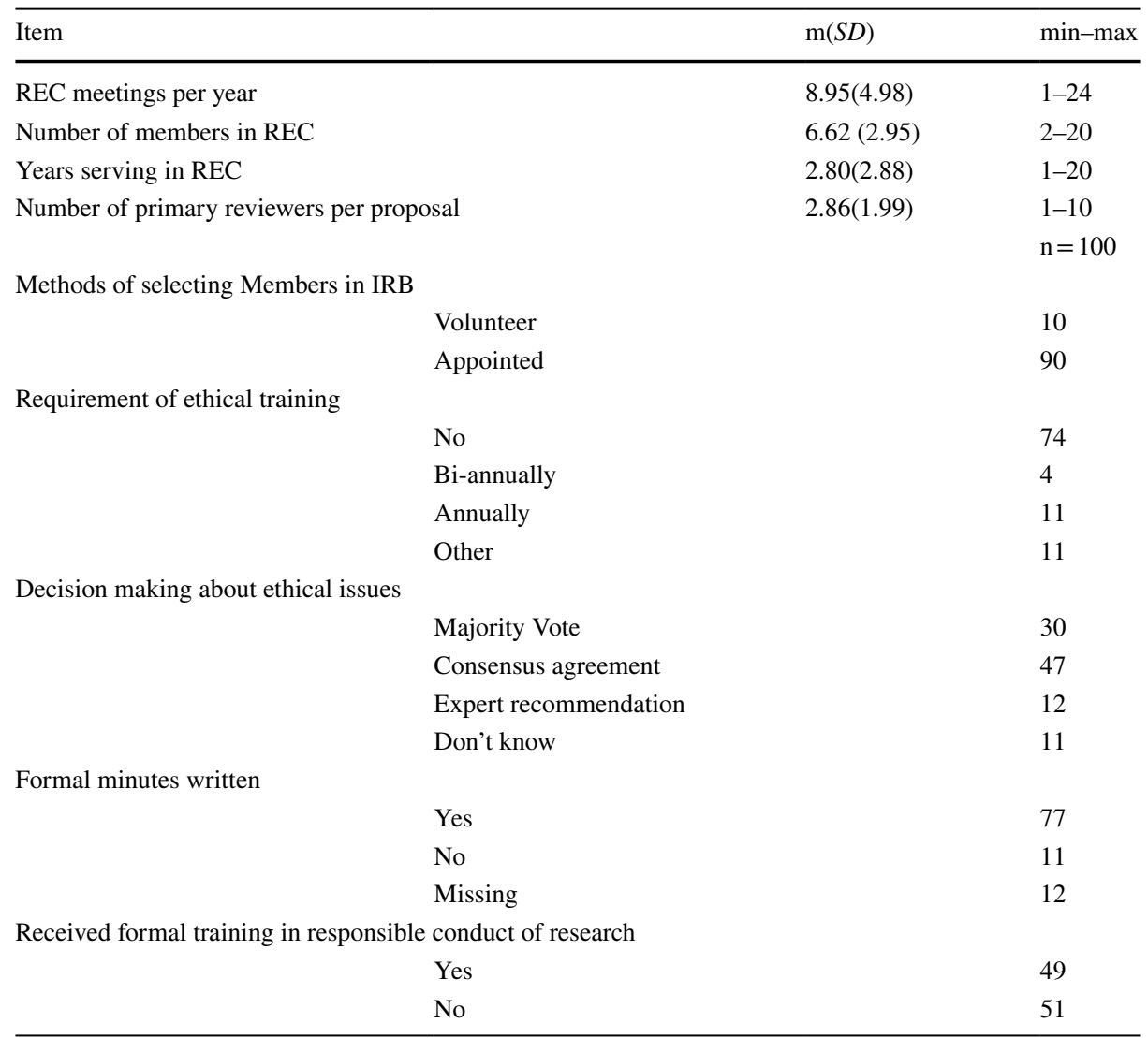

Table 4. The participants were divided equally regarding whether members of the committee have limited experience in research, i.e. 50\% disagreed and 50\% agreed. However, $69 \%$ of the participants disagreed that the members were not qualified to discuss research ethics issues, and $67 \%$ disagreed with the statement of ability to provide comments without justification. More than half of the participants believed that members of the RECs were unbiased, as $59 \%$ of them disagreed with the statement that members intentionally blocked studies, i.e. did not approve them for data collection although they fulfilled all requirements for ethical approval. 55\% of participants also disagreed that the members of RECs might be biased in assessing the work of a colleague or collaborator However, nearly three-quarters (72\%) agreed that members of RECs have different opinions regarding some ethical issues (Table 4).

Participants disagreed that REC members are reviewing many research papers (59\%). However, 55\% agreed with the statement that the RECs do not have a universal framework for analysing and making decisions about ethical dilemmas. A majority (70\%) also agreed that reviewing proposals takes a long time, and $67 \%$ agreed that they review proposals from different specialties. Furthermore, $61 \%$ of the participants agreed that RECs have limited ability to detect fraud. No significant differences were found between Omani and Jordanian 


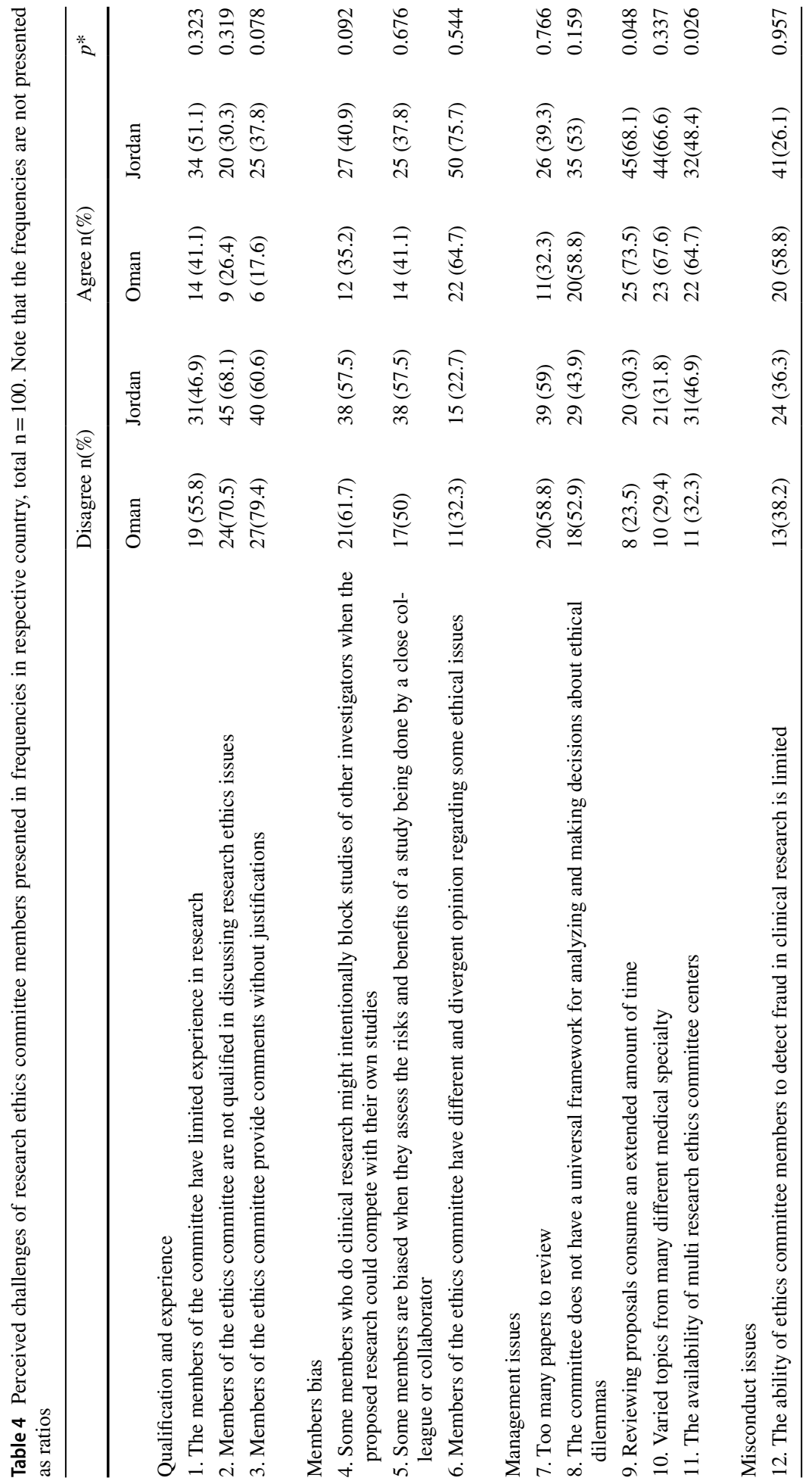


REC members except for the perception that reviewing proposals is a time-consuming task $(p=0.048)$ and that multi-research ethics committee centres are less available $(p=0.026)$ (Table 4).

The logistic regression analysis (Table 5) revealed a significant association between gender and location $(p=0.034)$, i.e. members 7.6 times (95\% CI: $1.17-50.13)$ more likely to be Jordanian. Members were also significantly less likely to have received formal training

Table 5 General factors, REC-related factors, and perceived challenges associated with being a researcher from Oman or Jordan. Highlighted values are either statistically significant $(p \leq 0.05)$ or statistically indicated $(p>0.05 \leq 0.1)$

\begin{tabular}{|c|c|c|c|c|c|c|c|c|}
\hline & \multirow[t]{2}{*}{ B } & \multirow[t]{2}{*}{ SE } & \multirow[t]{2}{*}{ Wald } & \multirow[t]{2}{*}{ df } & \multirow[t]{2}{*}{ Sig } & \multirow[t]{2}{*}{$\operatorname{Exp}(B)$} & \multicolumn{2}{|c|}{$\begin{array}{l}95 \% \text { CI for } \\
\text { EXP(B) }\end{array}$} \\
\hline & & & & & & & Lower & Upper \\
\hline \multicolumn{9}{|l|}{ General factors } \\
\hline Age & 0.11 & 0.08 & 1.70 & 1 & 0.192 & 1.11 & 0.95 & 1.30 \\
\hline Gender, Male (Female*) & 2.03 & 0.96 & 4.49 & 1 & 0.034 & 7.64 & 1.17 & 50.13 \\
\hline Private Institute (Governmental*) & -0.73 & 1.16 & 0.39 & 1 & 0.530 & 0.48 & 0.05 & 4.69 \\
\hline Currently a member in REC, No (Yes*) & 1.77 & 1.01 & 3.09 & 1 & 0.079 & 5.89 & 0.82 & 42.52 \\
\hline Experience in REC/IRB in years & -0.09 & 0.18 & 0.24 & 1 & 0.623 & 0.92 & 0.65 & 1.30 \\
\hline Profession, (College of Nursing*) & & & 4.75 & 3 & 0.191 & & & \\
\hline College of Medicine & 3.45 & 1.73 & 3.96 & 1 & 0.046 & 31.34 & 1.06 & 930.84 \\
\hline College of Pharmacy & 1.36 & 1.54 & 0.78 & 1 & 0.378 & 3.89 & 0.19 & 79.74 \\
\hline College of Health Sciences/Dentistry & 0.89 & 1.49 & 0.36 & 1 & 0.548 & 2.44 & 0.13 & 44.85 \\
\hline \multicolumn{9}{|l|}{ Factors related to REC routines } \\
\hline Number of members in the REC & 0.17 & 0.20 & 0.68 & 1 & 0.411 & 1.18 & 0.79 & 1.76 \\
\hline Selection method, Appointed (Volunteer*) & -1.55 & 1.44 & 1.17 & 1 & 0.280 & 0.21 & 0.01 & 3.55 \\
\hline Number of primary reviewers & 0.61 & 0.33 & 3.53 & 1 & 0.060 & 1.8 & 0.97 & 3.49 \\
\hline Decision making, (Consensus Agreement*) & & & 2.99 & 3 & 0.393 & & & \\
\hline Majority vote & -1.93 & 1.19 & 2.64 & 1 & 0.104 & 0.15 & 0.01 & 1.49 \\
\hline Expert recommendation & -0.87 & 1.71 & 0.26 & 1 & 0.610 & 0.42 & 0.02 & 11.93 \\
\hline Other & -1.00 & 1.91 & 0.28 & 1 & 0.600 & 0.37 & 0.01 & 15.58 \\
\hline Received formal training, No (Yes*) & -2.40 & 1.16 & 4.30 & 1 & 0.038 & 0.09 & 0.01 & 0.88 \\
\hline Required education, No (Yes*) & -0.04 & 1.01 & 0.001 & 1 & 0.972 & 0.97 & 0.14 & 6.93 \\
\hline \multicolumn{9}{|l|}{ Perceived Challenges } \\
\hline Qualifications of members & 0.59 & 0.34 & 3.04 & 1 & 0.081 & 1.81 & 0.93 & 3.51 \\
\hline Biased members & 0.12 & 0.28 & 0.19 & 1 & 0.665 & 1.13 & 0.66 & 1.94 \\
\hline Management issues & -0.78 & 0.30 & 6.84 & 1 & 0.009 & 0.46 & 0.26 & 0.82 \\
\hline Misconduct issues & 1.07 & 0.98 & 1.18 & 1 & 0.277 & 2.90 & 0.43 & 19.82 \\
\hline
\end{tabular}

${ }^{\text {a }}$ Variable(s) entered on step 1: Age, Gender, Organization form, Currently member in REC/IRB, Experience in years, Number of members in the REC, Selection of members, Number of primary reviewers, Decision making, Formal training, Required education, Qualifications of members, Bias in members, Management issues, Misconduct issues, Profession

${ }^{\mathrm{b}}$ Dependent variable: Location (Oman/Jordan)

c * Reference category

${ }^{\mathrm{d}}$ Omnibus Tests of Model Coefficient $=0.001$, Model Summary $($ Cox and Snell R Square $=0.437$; Nagelkerke R Square $=0.610)$, Hosmer and Lemeshow Goodness-of-fit Test $($ Chi-square $=11.961 ;$ Sig. $=0.153)$ 
if they came from Jordan ( $p=0.038, \mathrm{OR}=0.09,95 \%$ CI $0.01-0.88$ ). Similarly, being a faculty member in a College of Medicine was more likely to come from Jordan compared to being from a College of Nursing $(p=0.046, \mathrm{OR}=31.34,95 \%$ CI 1.06-930.84). There was significantly lower risk of facing more management issues if the participants came from Jordan $(p=0.009, \mathrm{OR}=0.46,95 \%$ CI $0.26-0.82)$. In addition, statistical associations were found between the location (Oman/Jordan) on one side and being currently a member of $\operatorname{REC}(p=0.079)$, the number of primary reviewers $(p=0.060)$, and the perceived qualifications of REC members ( $p=0.081)$ (Table 5).

The final model had a good fit and the variables explained $61 \%$ of the variation in the dependent variable (Hosmer and Lemeshow: $p=0.153$; Nagelkerke R Square $=0.610$ ). Finally, 32\% of the participants had witnessed cases of plagiarism, $21 \%$ inappropriate authorship, $20 \%$ lack of consent, and $17 \%$ data fabrication misconduct during their work on the REC.

\section{Discussion}

This paper compared the differences between the structure of Omani and Jordanian RECs and investigated the perceptions of the challenges affecting the work of the committee members. The findings showed that almost seven in ten of the participants disagree that the members of the RECs are unqualified and provide comments without justification; half believe that REC members have limited experience in research. Almost three quarters of the participants believe the RECs members have different opinions regarding some ethical issues. No significant differences were found between Omani and Jordanian REC members regarding the perception of the challenges except for the perception that reviewing proposals is a time-consuming task $(p=0.048)$ and that multi-research ethics committee centres are less available $(p=0.026)$.

The majority of the participants serving on REC committees perceived that members are qualified to discuss research ethics and justify their comments. Opinion was almost equally divided about the limited experience of REC members. Members of RECs are nominated to serve based on their certificate and previous research experience, which explains why the majority agree on these points (Ghooi, 2014; Mayo Clinic Human Research Protection Program, 2017). However, previous studies from the researchers' perspective found members with limited experience, unqualified and failing to justify their comments (Campbell, 2004; Clapp et al., 2017; Glasa et al., 2015). For example, Clapp et al. (2017) found that the majority of decision letters did not include justification in their comments.

Another of our findings was that $73.5 \%$ of Jordanian and $68.1 \%$ of Omani participants believed that reviewing proposals consumes a great amount of time. In a previous study, REC members considered themselves as guardians of the participants' rights, describing themselves as the parents; this explains why the process takes so long (Guillemin et al., 2012). Decision makers and REC members need to revaluate the time taken to evaluate proposals and give a clear timeframe to the researchers.

The current study also showed that more than half of the participants (59\%) disagreed with the statement that the members of RECs intentionally block or delay the acceptance of some proposals, again seeing themselves as parents who can judge the quality of the work and hence either approve or reject it (Guillemin et al., 2012). Previous studies, however, indicate that REC members may intentionally block studies (Ghersi, 2004). The possible explanation is that the REC members are researchers with 
competing interests which may result in bias activity and delay the ethical clearance process (Cook \& Hoas, 2011). Comparative studies are needed to assess the perspective of ethics committee members against those of the researchers who need their approval. Understanding the nature of these differences may help decision makers to develop new policies, regulations, or interventions. For example, educational programmes can help bridge the gap between the RECs and the researchers.

The results of the current study showed that the majority of REC members are serving without being certified or having advance training in ethics, and that there is no specific requirement such as attending further ethical training. to continue serving in the committees. Similarly, a recent Jordanian study exploring researchers' attitudes and perceptions toward REC members found that participants raised concern regarding members' level of training and knowledge regarding medical ethics (Ayoub et al., 2019). There is a need to recruit members who are qualified, certified, and with experience (Amdur \& Bankert, 2010). Decision makers can facilitate this by establishing a platform for training researchers in ethics-related matters; they can sponsor Arab researchers to complete higher degrees in research and ethics. In 2015, a new one-year research ethics programme was established for Arab participants at Jordan University of Science and Technology (JUST) in collaboration with the University of California San Diego (UCSD). At the end of the programme, candidates are awarded a University of California San Diego Fellow Graduate Certificate in Research Ethics, specifically aimed at faculty members in colleges of medicine, dentistry, pharmacy, nursing, and health sciences (Jordan University of Science \& Technology, 2018). The majority of those recruited to the programme were Jordanians, which might explain our finding of an association between having received formal training and the presence of fewer management issues in being a member of a REC in Jordan. The current Jordanian programme and the Middle East Research Ethics Training Initiative are both related to research ethics in the Middle East and Arab region (Mereti-Network, 2017). Although there is no research evaluating the impact of such programmes on researchers' level of knowledge, these programmes are considered good initiatives to improve the ethics and research literacy among Arab faculty members. Therefore, this experience needs to be expanded and replicated, as currently there are no such programmes in Oman.

Participants in the current study reported that the RECs in Oman and Jordan lack a universal framework for analysing and making decisions. Nevertheless, both have regulatory bodies that control and maintain good research practices nationally. For Jordan, RECs act in a much-regulated way and follow clear guidelines provided by the Jordanian FDA (AlOmari \& Al-Hussaini, 2017). Similar findings were reported in a study evaluating ethics committees at Turkish universities (Eksioglu et al., 2015). However, the authors recommended establishing a universal framework to counteract any breach of ethics or scientific research principles (Eksioglu et al., 2015). Ekberg (2012) provided a set of guidelines and recommendations for REC committee members, which could be used as the foundation for a framework to be developed and used by REC member in Oman and Jordan. This will help in solving many of the ethical issues that the committee members currently encounter. Another good practice adopted by South Africa can help in improving the capacity of REC members is adopting a unified legislative framework at the national level. The National Research Ethics Council of South Africa is a regulatory oversight body and is responsible for research ethics guidance and the registration of research ethics committees. The issue of reciprocity for ethics review is still determined at a local level (Department of Health [South Africa], 2015). This will help in streamlining the process, reducing the number of approvals required when researchers apply to more than one institution, in turn expediting 
the process of ethical approval (Davies, 2020). Decision makers in Oman and Jordan can adopt such good practices.

In conclusion, RECs in Jordan and Oman need to address and counter challenges in order to improve the quality of research activities, and in particular clinical research. There is no good research without good ethics.

\section{Best Practice}

Jordan RECs work according to guidelines provided by the Jordanian FDA, and Oman is working according to the Ministry of Health regulations. Researchers in both countries, in collaboration with experts in the field, need to improve the current national frameworks to adhere to international standards. This will help in solving many of the ethical issues that REC members are facing.

Based on our findings, there is also a need to recruit REC members who are qualified, certificated, and with experience. However, it is important to note that our results have limited generalizability because of the narrow sample size, despite the broad variety of universities, experience and cultural contexts.

\section{Research Agenda}

A similar study with a qualitative approach could shed the light on the challenges experienced, with greater nuance and value at all stages, from the recruitment of eligible and qualified committee members to decision-making processes. That is, qualitative research may help in providing in-depth and personal description of the phenomena under study, better identifying and explaining the unique challenges from the perspective of Arab REC members. For example, focus groups can help achieve such as goal.

In addition, there is a need for studies to compare the perspective of ethics committee members with that of the researchers who seek their approval. Understanding the nature of any differences may help decision makers to develop new policies or educational programmes to bridge the gap between the RECs and the researchers.

\section{Limitations and Strengths of the Study}

This study does not come without limitations. The data collection method was a selfreporting survey, which might increase the risk of self-reporting bias, and thus affect the generalizability of the findings. In addition, participants who were not currently active REC members relied on memories of routines followed during their time, which might be subject to recall bias. More widely, the generalizability of the study's findings are limited to the Jordan and Oman. Although the convenience sampling technique was yet another limitation, the fact that $88 \%$ of the participants were at the professorial level is considered a strength of the study. Overall, our results can be considered as a red flag for decision makers in the academic institutions to appoint well trained professors to the RECs.A broad spectrum of universities was contacted, so participants' responses reflect a variety of experience related to the context and internal culture of the respective universities. Nevertheless, there is a need to replicate the study and increase the sample size, particularly in Oman. 


\section{Educational Implications}

A training programme for all faculty members in both Omani and Jordanian universities should be mandatory and a pre-requisite for joining ethics committees. Furthermore, good ethics practices should be integrated part in the curricula of students in all humanities and medical professions.

Authors Contributions All authors contributed to the study conception and design. Material preparation and data collection were performed by $[\mathrm{OAO}]$ and $[\mathrm{MMK}]$. The analysis was conducted by $[\mathrm{AK}]$ and $[\mathrm{OAO}]$ while [MAQ], [WAD], and [IT] contributed to the interpretation. The first draft of the manuscript was written by all authors. Further, all authors read and approved the final manuscript.

Funding Open access funding provided by Kristianstad University. This research did not receive any funding.

Availability of Data and Materials The datasets generated and/or analysed during this study are available from the corresponding author on reasonable request.

\section{Declarations}

Ethics Approval This proposal was approved by the Ethics Committee of the College of Nursing at Sultan Qaboos University (Protocol no. 18/2018).

Consent to Participate A clear statement was given to participants that accessing the questionnaire was considered a decision to give consent and take part in the study. However, and to maintain the anonymity of the participants, the Google Forms was programmed to not link the responses with participants' email IDs, so the consents were not documented.

Conflict of Interest The authors declare that they have no conflicts of interest.

Open Access This article is licensed under a Creative Commons Attribution 4.0 International License, which permits use, sharing, adaptation, distribution and reproduction in any medium or format, as long as you give appropriate credit to the original author(s) and the source, provide a link to the Creative Commons licence, and indicate if changes were made. The images or other third party material in this article are included in the article's Creative Commons licence, unless indicated otherwise in a credit line to the material. If material is not included in the article's Creative Commons licence and your intended use is not permitted by statutory regulation or exceeds the permitted use, you will need to obtain permission directly from the copyright holder. To view a copy of this licence, visit http://creativecommons.org/licenses/by/4.0/.

\section{References}

Al-Omari, A., \& Al-Hussaini, M. (2017). Research ethics governance in the Arab region: Jordan. In Research ethics in the Arab region (pp. 221-228). Springer.

Amdur, R. J., \& Bankert, E. A. (2010). Institutional review board: Member handbook. Jones \& Bartlett Publishers.

American University of Beirut (AUB). (2020). Institutional review board Retrieved 20th of Feb from https://www.aub.edu.lb/irb/Pages/Aboutus.aspx\#: :text=\%E2\% 80\%8BThe\%20IRB\%20was\% 20 founded,newly\%20established\%20HRPP\%20in\%202010

Ayoub, N. M., Qandil, A. M., \& McCutchan, J. A. (2019). Knowledge, attitudes, and practice regarding research ethics committees among health care faculty at two public universities in Jordan. Journal of Empirical Research on Human Research Ethics, 14(4), 372-382.

Beirut Arab University. (2017). Institutional Review Board. Beirut Arab University Publications. https:// www.bau.edu.lb/BAUUpload/Library/Files/pdf/IRB/BAU\%20IRB\%20Guidelines.pdf 
Bhutta, Z. A. (2002). Ethics in international health research: a perspective from the developing world. Bulletin of the World Health Organization, 80, 114-120.

Campbell, E. G. (2004). Concerns about IRBs in the enterprise of clinical research. THE LANCET Oncology, $326-327$.

Centre of Studies and Research Directorate Gneral of Planning and Studies. (2016). Guidelines For Responsible Conduct of Clinical Studies and Trials Minestry of Health[Oman]. Retrieved 26th of August from https://mohcsr.gov.om/wp-content/uploads/2016/01/Guide_ClinicalStudiesTrials_Aug16.pdf

Clapp, J. T., Gleason, K. A., \& Joffe, S. (2017). Justification and authority in institutional review board decision letters. Social Science \& Medicine, 194, 25-33.

Cook, A. F., \& Hoas, H. (2011). Protecting research subjects: IRBs in a changing research landscape. $I R B, 33(2), 14$.

Davies, S. E. (2020). The introduction of research ethics review procedures at a university in South Africa: review outcomes of a social science research ethics committee. Research Ethics, 16(1-2), $1-26$.

Department of Health [South Africa]. (2015). Department of Health. Ethics in Health Research - Principles, processes and structures. Retrieved 27th of August from https://www.ru.ac.za/media/ rhodesuniversity/content/ethics/documents/nationalguidelines/DOH_(2015)_Ethics_in_health_ research_Principles,_processes_and_structures.pdf

Ekberg, M. (2012). Reassessing the role of the biomedical research ethics committee. Journal of Academic Ethics, 10(4), 335-352.

Eksioglu, S., Sezer, H. B. M., \& Cicek, F. G. (2015). Ethics committees in Turkish universities. Procedia-Social and Behavioral Sciences, 174, 2882-2890.

El-Dessouky, H. F., Abdel-Aziz, A. M., Ibrahim, C., Moni, M., Abul Fadl, R., \& Silverman, H. (2011). Knowledge, awareness, and attitudes about research ethics among dental faculty in the Middle East: A pilot study. International journal of dentistry, 2011.

Ghersi, D. (2004). The future of institutional review boards. THE LANCET Oncology, 5(5), 325-329.

Ghooi, R. B. (2014). Institutional review boards: Challenges and opportunities. Perspectives in clinical research, 5(2), 60-65. https://doi.org/10.4103/2229-3485.128020

Glasa, J., Krčméryová, T., \& Glasová, H. (2015). Research Ethics Committees In Slovakia: 25 Years Of Developments And New Challenges. Clinical Therapeutics, 37(8), e148.

Grady, C. (2015). Institutional review boards: purpose and challenges. Chest, 148(5), 1148-1155.

Guillemin, M., Gillam, L., Rosenthal, D., \& Bolitho, A. (2012). Human research ethics committees: examining their roles and practices. Journal of Empirical Research on Human Research Ethics, 7(3), 38-49.

Hyder, A. A., Wali, S. A., Khan, A. N., Teoh, N. B., Kass, N. E., \& Dawson, L. (2004). Ethical review of health research: a perspective from developing country researchers. Journal of Medical Ethics, 30(1), $68-72$.

Jordan University of Science and Technology. (2018). Research Ethics Program In Jordan. Retrieved 13 August from https://jordanrcrprogram.com/

Kass, N. E., Hyder, A. A., Ajuwon, A., Appiah-Poku, J., Barsdorf, N., Elsayed, D. E., Mokhachane, M., Mupenda, B., Ndebele, P., \& Ndossi, G. (2007). The structure and function of research ethics committees in Africa: A case study. PLoS medicine, 4(1), e3.

Makhoul, J., El-Alti, L., Qutteina, Y., Nasrallah, C., Sakr, C., Nakkash, R., \& Alali, K. (2014). "Protecting" or "Policing" Academic Researchers' View of IRBs in an Arab Context. Journal of Empirical Research on Human Research Ethics, 9(5), 25-35.

Matar, A., \& Silverman, H. (2013). Perspectives of Egyptian research ethics committees regarding their effective functioning. Journal of Empirical Research on Human Research Ethics, 8(1), 32-44.

Mayo Clinic Human Research Protection Program. (2017). Roles, Qualifications and Evaluation of IRB Members Retrieved 22nd of Feb from https:/www.mayo.edu/research/documents/9-rolesqualification-and-eval-of-irb-memberspdf/doc-10027103\#: :text=Scientific\%20Committee\% 20Member,Bachelor\%20of\%20Science $\% 20$ in $\% 20$ Nursing

Mereti-Network. (2017). MERETI Network Retrieved 27th of August from http://www.mereti-network. net/page/33/

Ministry of Health [Oman]. (2011). Oman Pharmaceutical Country Profile. Retrieved 26th of August from https://www.who.int/medicines/areas/coordination/OmanPSCP_Narrative2012-02-08-Final.pdf?ua=1

National Ministry of Health [Sudan]. (2015). Health Research in Sudan. Retrieved 26th of August from https://sites.google.com/site/healthresearchlibrary/HealthResearchinSudan

Nyika, A., Kilama, W., Tangwa, G. B., Chilengi, R., \& Tindana, P. (2009). Capacity building of ethics review committees across Africa based on the results of a comprehensive needs assessment survey. Developing world bioethics, 9(3), 149-156. 
Rababa'h, A. M., Alzoubi, K. H., Ababneh, M., \& Khabour, O. F. (2020). Awareness of Jordanian Investigators About the Importance of Ethics Review Committees: A Pilot Study. Science and engineering ethics, 26(2), 821-831.

Ramahi, I., \& Silverman, H. (2009). Clinical research law in Jordan: an ethical analysis. Developing world bioethics, 9(1), 26-33.

Shafout, E. Y., \& Mahrouq, S. A. (2014). Clinical trials in Jordan: Current status and improvement opportunities. Clinical Researcher. Retrieved 26th of August from http://www.jfda.jo/EchoBusV3. 0/SystemAssets/PDF/AR/\%D8\%AF\%D8\%B1\%D8\%A7\%D8\%B3\%D8\%A7\%D8\%AA\%20\%D9\% $88 \% \mathrm{D} 8 \% \mathrm{~A} 8 \% \mathrm{D} 8 \% \mathrm{AD} \% \mathrm{D} 9 \% 88 \% \mathrm{D} 8 \% \mathrm{AB} / 1 . \mathrm{pdf}$

Silverman, H., Edwards, H., Shamoo, A., \& Matar, A. (2013). Enhancing research ethics capacity in the Middle East: Experience and challenges of a Fogarty-sponsored training program. Journal of Empirical Research on Human Research Ethics, 8(5), 40-51.

Silverman, H., Sleem, H., Moodley, K., Kumar, N., Naidoo, S., Subramanian, T., Jaafar, R., \& Moni, M. (2015). Results of a self-assessment tool to assess the operational characteristics of research ethics committees in low-and middle-income countries. Journal of Medical Ethics, 41(4), 332-337.

Sleem, H., El-Kamary, S. S., \& Silverman, H. J. (2010). Identifying structures, processes, resources and needs of research ethics committees in Egypt. BMC Medical Ethics, 11(1), 12.

Tarboush, N. A., Alkayed, Z., Alzoubi, K. H., \& Al-Delaimy, W. K. (2020). The understanding of research ethics at health sciences schools in Jordan: a cross-sectional study. BMC medical education, 20, 1-8.

World Health Organization. (2009). Research ethics committees: basic concepts for capacity-building. World Health Organization.

World Medical Association (WMA). (2008). World Medical Association Declaration of Helsinki: Ethical principles for medical research involving human subjects. 59th WMA General Assembly, Seoul, South Korea. Retrieved 25th of August from https://www.wma.net/policies-post/wma-declaration-of-helsinkiethical-principles-for-medical-research-involving-human-subjects/

Publisher's Note Springer Nature remains neutral with regard to jurisdictional claims in published maps and institutional affiliations.

\section{Authors and Affiliations}

\section{Omar Al Omari ${ }^{1,2} \cdot$ Atika Khalaf $^{1,3}$ (D) Wael Al Delaimy ${ }^{4} \cdot$ Mohammad Al Qadire $^{1,5}$. Moawiah M. Khatatbeh ${ }^{6} \cdot I_{\text {mad Thultheen }}{ }^{7}$}

Omar Al Omari

o.alomari@squ.edu.om

Wael Al Delaimy

waldelaimy@ucsd.edu

Mohammad Al Qadire

m.alqadire@squ.edu.om

Moawiah M. Khatatbeh

moawia.m@yu.edu.jo

Imad Thultheen

imad.t@najah.edu

1 College of Nursing, Sultan Qaboos University, Muscat, Oman

2 School of Nursing Midwifery and Paramedicine, Curtin University, Perth, Australia

3 Faculty of Health Science, Kristianstad University, Elmetorpsvägen 15, 29188 Kristianstad, SE, Sweden

4 Family Medicine and Public Health, University of California, San Diego, USA

5 College of Nursing, Al Al-Bayt University, Al-Mafraq, Jordan

6 Department of Basic Medical Sciences, Faculty of Medicine, Yarmouk University, Irbid, Jordan

7 Faculty of Medicine and Health Science, An-Najah National University, Nablus, Palestine 